\title{
Device performance enhancement of polymer solar cells by nanoparticle self-assembly
}

\author{
Wenluan Zhang, ${ }^{\mathrm{a}, *}$, Ngoc A. Nguyen ${ }^{\mathrm{a}, 1}$, Roy Murray ${ }^{\mathrm{b}}$, Michael E. Mackay ${ }^{\mathrm{a}, \mathrm{c}, *}$ \\ ${ }^{a}$ Department of Materials Science \& Engineering, University of Delaware, Newark, DE, \\ 19716, USA \\ ${ }^{b}$ Department of Physics and Astronomy, University of Delaware, Newark, DE, 19716, USA \\ ${ }^{c}$ Department of Chemical \& Biomolecular Engineering, University of Delaware, Newark, \\ $D E, 19716, U S A$
}

\begin{abstract}
We show that it is possible to assemble a sparse mono-layer of $\mathrm{Fe}_{3} \mathrm{O}_{4}$ nanoparticles (NPs) at cathode interface of a polymer solar cell based on poly(3-hexylthiophene):[6,6]phenyl- $\mathrm{C}_{60}$-butyric acid methyl ester (P3HT:PCBM) through the synergic effect of strong convective outflow, surface energy, $\mathrm{Fe}_{3} \mathrm{O}_{4} \mathrm{NPs}$ concentration and active layer thickness. When the distance between those $\mathrm{Fe}_{3} \mathrm{O}_{4} \mathrm{NPs}$ is smaller than the size of P3HT, the P3HT is excluded from the inter-particle space, and fullerene molecules fill in the space to build electron transport pathways improving charge transport and collection near cathode interface proved by transmission electron microscopy and X-ray photoelectron spectroscopy. The power conversion efficiency of the devices is improved up to $20 \%$. The bulk morphology of light absorbing layers is not affected by the addition of $\mathrm{Fe}_{3} \mathrm{O}_{4} \mathrm{NPs}$ as demonstrated by neutron and X-ray scattering results.

Keywords: Polymer:fullerene solar cells, nanoparticle self-assembly, depletion flocculation, spin coating, neutron scattering

2016 MSC: 00-01, 99-00

\footnotetext{
* Corresponding author

Email addresses: jasonzwl@udel.edu (Wenluan Zhang), mem@udel.edu (Michael E. Mackay)

${ }^{1}$ Current address: Materials Science and Technology Division, Oak Ridge National Lab, Oak Ridge, TN 37831
}

Preprint submitted to Journal of ${ }^{A} T_{E} X$ Templates

October 8, 2016

(C) 2016. This manuscript version is made available under the Elsevier user license http://www.elsevier.com/open-access/userlicense/1.0/ 


\section{Introduction}

High interest has arisen in the field of organic solar cells during the past two decades, especially for polymer:fullerene solar cells because of their potential for low cost and fast roll-to-roll production on a flexible light weight substrate [1, 2, 3]. The sunlight shines through the transparent electrode to generate excitons, i.e., Coulomb-bound electron-hole pairs, in the polymer going to the interfaces of polymer and fullerene for separation to generate charge carriers. The charge carriers then transport to their electrodes respectively to output current. Because the diffusion length of these excitons is relatively short, approximately $10 \mathrm{~nm}$, a less phase separated intimate mixing structure is preferred for efficient exciton separation [4]. However, sufficient charge transport requires a continuous pure electron donor and acceptor phase, so a trade off between exciton separation and charge transport must be taken into consideration.

Based on this, a vertical comb-like structure was proposed to be an ideal morphology for polymer:fullerene solar cells with a balanced weight ratio [5]. In this design, 5-10 $\mathrm{nm}$ thick layer of pure polymer and fullerene is adjacent to anode and cathode respectively. The sandwich layer between these two is composed of interdigitated polymer and fullerene with 10-20 nm width to ensure efficient exciton diffusion and avoid the trap of free charge carrier in each phase due to the lack of long-range order in organic materials. To obtain such a delicate structure on nanometer scale is always challenging. Therefore, in practice, the polymer and fullerene are blended to form a phase separated interpenetrating structure at nanometer scale creating the so called bulk-heterojunction (BHJ) to harvest the light [6]. The resulted morphology is usually vertical symmetric and homogeneous, so one deviation from the ideal design is no pure material phases formed at the contact interfaces, which is not beneficial to charge collection [7].

To break this morphological symmetry to improve the device performance, polymer rich layer needs to be formed near anode side, and fullerene rich layer, cathode side. For the well-studied system of poly(3-hexyl thiophene):[6,6]phenyl- $\mathrm{C}_{61}$-butyric acid methyl ester (P3HT:PCBM), Germack et al. lowered 
the surface energy of the hole transporting layer to successfully increase P3HT volume fraction from $47 \%$ to almost $100 \%$ near anode [8]. However, no significant difference was observed in the device performance. To have a more delicate nanostructure, the nanoimprint lithography method was applied to produce P3HT nanopillar on the anode and deposit PCBM afterward to realize the comb-like morphology [9, 10, 11]. However, this method can only provide precise control of morphology above $50 \mathrm{~nm}$ length scale, which is not small enough for any significant efficiency improvement, and its complicated fabrication process appears challenging to be commercialized.

Considering the difficulties in manipulating P3HT morphology near the anode and the non-significant device performance improvement even after obtaining such delicate nanostructure, an alternative approach would be to focus on modifying the PCBM morphology near the cathode. Previously, Kiel et al. used phase sensitive neutron reflectivity finding higher PCBM concentration near air interface (which is cathode side in the device structure) after thermal annealing due to their slightly lower surface energy compared with P3HT and the convective flow during spin coating process [12, 13]. This morphology change was accompanied with a significant $140 \%$ enhancement in power conversion efficiency (PCE). However, since the P3HT crystallinity and PCBM agglomerates also evolved after thermal annealing to have higher degree of phase separation to benefit the device performance, it is unclear what the role of high PCBM concentration near cathode is in improving PCE [14]. So it is necessary to study this PCBM concentration effect near cathode without affecting the bulk morphology of the active layers.

Since the P3HT:PCBM active layer is a thin film composed of nanoparticle and polymer, we considered applying nanoparticle self-assembly to realize the objective morphology. In the process of self-assembly, some forces are usually involved, such as entropic, enthalpic and long-range dispersion forces. Some kinetic effects like jamming and self-assembly in drying are also needed to be considered when the complete system is at non-equilibrium status [15, 16. In this study, the depletion flocculation effect was used to obtain the desired mor- 
(a)

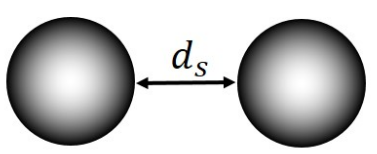

(b)
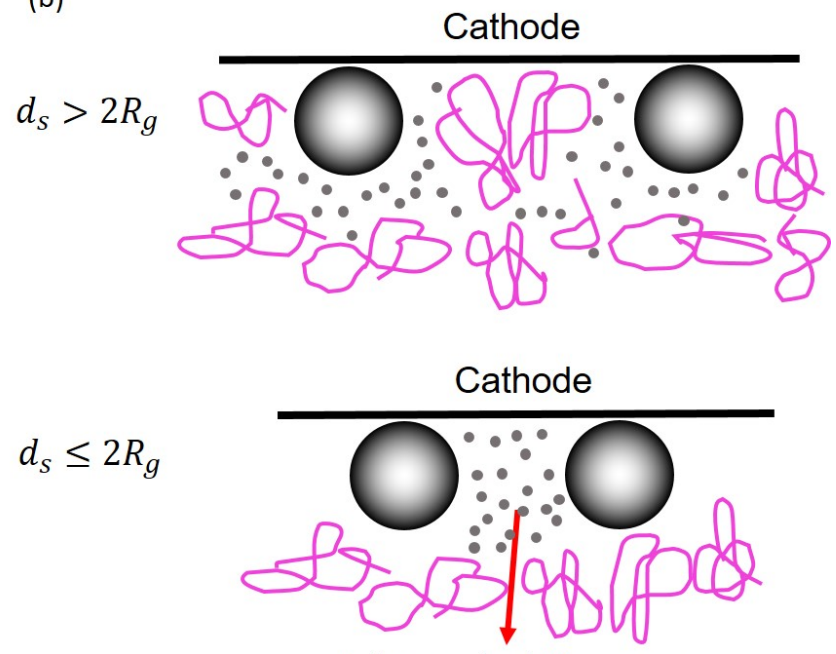

Polymer depletion zone

- PCBM

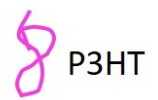

Figure 1: (a) $d_{s}$ is the inter-particle distance between two nanoparticles; (b) when $d_{s}$ is smaller than $2 R_{g}$ of $\mathrm{P} 3 \mathrm{HT}$, the polymer is excluded to have polymer depletion zone and PCBM molecules fill the space between the two particles so that more PCBM could be found near cathode. 
phology. This phenomenon was originally observed in colloidal dispersions such as the aggregation of red blood cells in the polymer solution. Polymer molecules are excluded from the interstices between two particles forming polymer depletion zone of pure solvent, when the inter-particle distance is less than the diameter of the free polymer coil. The driving force for the formation of polymer depletion zone is the conformational entropy loss from the polymer coils since they lose more degrees of freedom than solvent molecules in the interstices between the particles 17, 18. Similarly, if nanoparticles were mixed into a blend of P3HT:PCBM, when the inter-particle distance is smaller than $2 R_{g}\left(R_{g}\right.$ is radius of gyration) of $\mathrm{P} 3 \mathrm{HT}$, the polymer depletion zone could be created for PCBM molecules to fill in acting as solvent molecules, since radius of PCBM $(\sim 0.35 \mathrm{~nm})$ is much smaller than the $R_{g}$ of $\mathrm{P} 3 \mathrm{HT}$, which is about $3-10 \mathrm{~nm}$, considering it is polydisperse (PDI $=1.4)[19,20]$. By choosing particles with a lower surface energy than P3HT and PCBM, with the aid from a strong convective flow of spin coating, the segregation of them to the air interface could be obtained. Therefore a PCBM rich region could be formed building continuous electron pathways near cathode and further improving the charge collection. This process is shown in Figure 1 .

In this study, we mixed $11 \mathrm{~nm}$ diameter $\mathrm{Fe}_{3} \mathrm{O}_{4}$ nanoparticles (NPs) into P3HT:PCBM system to investigate their impact on the morphology and device performance. Since these NPs do not scatter light, the optical effect like Mie scattering can be excluded to simplify the analysis. Moreover, these NPs are insulators so only morphological factor is needed to be studied. $\mathrm{Fe}_{3} \mathrm{O}_{4} \mathrm{NPs}$ vertical distribution in the P3HT:PCBM active layers were observed using transmission electron microscopy (TEM). Small angle neutron scattering (SANS) and grazing incidence X-ray diffraction (GIXRD) were used to characterize the morphological change of PCBM and P3HT. X-ray photoelectron spectroscopy (XPS) was used to study the composition of the active layers' top interface. Two different thicknesses of the active layers, and a series of $\mathrm{Fe}_{3} \mathrm{O}_{4} \mathrm{NPs}$ volume fraction addition was studied to find out the condition for optimum device performance. 


\section{Experimental Section}

ITO (indium tin oxide) coated one inch square glass (resistance of 8-12 $\Omega / \square$, Delta technologies, LTD) was cleaned by ultrasonic treatment in acetone and isoproponal sequentially for 10 minutes. All the substrates were pretreated by ultraviolet ozone plasma for 15 minutes. This was followed by spin coating a $33 \mathrm{~nm}$ thick layer of poly(3,4-ethylenedioxythio-phene):poly(styrenesulfonate) (PEDOT:PSS, H.C. Starck, Al 4083) which was then transferred to an oven and annealed for $20 \mathrm{~min}$ at $\sim 130{ }^{\circ} \mathrm{C}$. After this, the substrate was transferred to a nitrogen-filled glove box to fabricate solar cell devices. The solutions required for spin coating the active layer were prepared by dissolving P3HT (from Luminescence Technology Corp., $M_{n}=55,000 \mathrm{~g} / \mathrm{mol}, \mathrm{PDI}=1.4$ ) and $\mathrm{PC}_{61} \mathrm{BM}$ (from Nano-C) in di-ortho-chlorobenzene with specific $\mathrm{Fe}_{3} \mathrm{O}_{4}$ nanoparticle concentrations in a nitrogen glove box to have 1:1 weight ratio $\mathrm{P} 3 \mathrm{HT}$ :PCBM solution with $20 \mathrm{mg} / \mathrm{ml}$ concentration for each composition. A series of $\mathrm{Fe}_{3} \mathrm{O}_{4}$ NPs (EMG1300, hydrodynamic diameter $\sim 11 \mathrm{~nm}$, density $2.85 \mathrm{~g} / \mathrm{cm}^{3}$, from Ferrotec, size distribution is shown in Figure S1) volume fraction in solid content was obtained from 0 to 20 vol\% (calculated by using each component's density and weight fraction). To have complete dissolution, the solution was stirred 24 hours at $40{ }^{\circ} \mathrm{C}$. A $0.45 \mu \mathrm{m}$ Teflon filter was used during the spin coating process. To investigate the thickness effect on the device performance, the solution was spin coated at $600 \mathrm{rpm}$ for 60 seconds to obtain approximately $230 \mathrm{~nm}$ thickness and $1800 \mathrm{rpm} 30$ seconds for $90 \mathrm{~nm}$ thickness. The obtained thicknesses were controlled by the spin coating condition, not the amount of $\mathrm{Fe}_{3} \mathrm{O}_{4}$ NPs. The spun-coated active layers were thermal annealed on a preheated hotplate at $110{ }^{\circ} \mathrm{C}$ for 10 minutes to obtain high degree of P3HT polycrystalline. Lithium fluoride (0.8 nm thickness) and aluminum (80 nm thickness) were sequentially thermal evaporated in a deposition chamber at a vacuum of $2 \times 10^{-6}$ mbar. The working device area was approximately $0.1 \mathrm{~cm}^{2}$. The current-voltage curves were measured with a Keithley 2400 source meter, under illumination of $100 \mathrm{~mW} / \mathrm{cm}^{2}$ from $150 \mathrm{~W}$ solar simulator with AM1.5G filters. 
8 data points were collected for each sample from 8 different devices under the same condition. A $95 \%$ confidence interval was used when the collected data were averaged. All materials were used as received.

For characterizations other than the current-voltage test, the samples were prepared on soda-lime glass instead of ITO glass. To make cross-section images of thin films of P3HT:PCBM with $\mathrm{Fe}_{3} \mathrm{O}_{4}$, all films coated on glass were floated off in deionized water and then picked up by a piece of epoxy resin (Spurr's kit from Electron Microscopy Sciences), and then sputtered with a marker layer of $\sim 20 \mathrm{~nm}$ gold. After that, a drop of epoxy resin (Spurr's kit) was deposited onto the samples and then cured at $40{ }^{\circ} \mathrm{C}$ for $24 \mathrm{~h}$. All ultramicrotomy was performed on a Reichert Jung Microtome to have a film with about 70-80 nm thickness and images were taken with a JEM-2010F transmission electron microscope operated at $200 \mathrm{kV}$.

For neutron experiments, all the films were floated on water and picked up by a one inch diameter (100) double side polished silicon wafer. This process was repeated five times for each wafer. Since silicon is virtually transparent to neutrons, a stack of 3 wafers was used as one sample to have a total of 15 films to increase the scattering signal. The NG3 instrument was used for the neutron scattering experiment. Three detector distances and two neutron wavelengths were used: distances of 1.33 and 4 meters were used with a wavelength of $6 \AA$ and 13.2 meters with $8.4 \AA$. Data were obtained over the scattering vector $(q)$ range of $0.008 \leq q \leq 0.3 \AA^{-1}$, where $q=(4 \pi / \lambda) \sin (\theta / 2)$, and a total scattering count of $\sim 10^{6}$ was used to increase the $\mathrm{S} / \mathrm{N}$ (signal to noise) ratio. Empty cell scattering and background scattering were performed for data conversion to absolute scattering intensity versus scattering vector. Data reduction and SANS analysis were performed using NCNR SANS packages SANS Reduction v5.20 and SANS Analysis v7.20 [21]. The incoherent scattering background was obtained by plotting $q^{4} I(q)$ versus $q^{4}$ at high- $q$ regime [22]. The slope of this plot is the sum of the incoherent scattering and a thermal scattering contribution both of which can be easily subtracted from the total scattering intensity. The magnitude of the background for all samples was small and around $0.7-1.4 \mathrm{~cm}^{-1}$. 


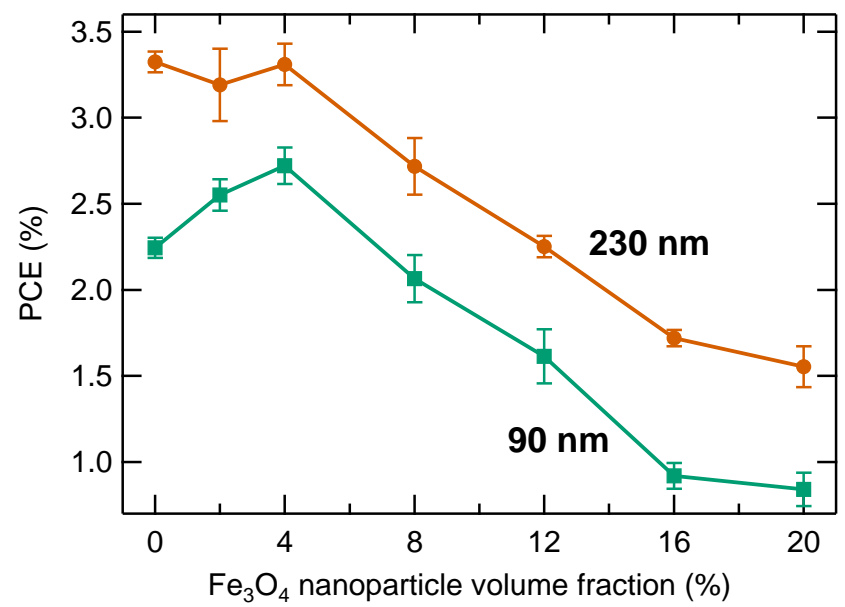

Figure 2: Power conversion efficiency as a function of $\mathrm{Fe}_{3} \mathrm{O}_{4} \mathrm{NPs}$ volume fraction in P3HT:PCBM initial blend. Orange data set is from samples with $230 \mathrm{~nm}$ thickness active layer, and green one from ones with $90 \mathrm{~nm}$ thickness active layer.

For grazing incidence X-ray diffraction, $0.5^{\circ}$ was used as the incident angle to perform all the scattering measurements on a Rigaku Ultimate IV multipurpose XRD system which used a $1.54 \AA$ wavelength Copper K source.

Atomic percentages were verified using X-ray photoelectron spectroscopy (XPS). All XPS measurements were carried out on a Surface Science machine using monochromated Al k-alpha radiation (1486.6 eV). Peak positions were internally referenced to the $\mathrm{C} 1$ s peak located at $284.6 \mathrm{eV}$ to correct for charging effect.

\section{Results and Analysis}

Figure 2 shows the power conversion efficiency (PCE) as a function of $\mathrm{Fe}_{3} \mathrm{O}_{4}$ NPs volume fraction in the initial solid content blend of P3HT:PCBM. For convenience, the samples having $230 \mathrm{~nm}$ thickness will be named as $230 \mathrm{~nm}$ samples, and the samples having $90 \mathrm{~nm}$ thickness as $90 \mathrm{~nm}$ samples in the rest of this study. Since the $230 \mathrm{~nm}$ samples are much thicker, more light is harvested leading to higher short circuit current density $\left(J_{\mathrm{SC}}\right.$, shown in Figure S2) and hence 
higher PCE. For $230 \mathrm{~nm}$ samples, there is not any significant enhancement in PCE with the addition of $\mathrm{Fe}_{3} \mathrm{O}_{4}$ NPs, and the samples with NPs vol\% above 4 have even lower device performance. However, for $90 \mathrm{~nm}$ samples, the addition of $4 \mathrm{vol} \% \mathrm{Fe}_{3} \mathrm{O}_{4}$ NPs increases efficiency from $2.24 \%$ to $2.70 \%$ in comparison with the control (neat) P3HT: PCBM sample. Thus, P3HT:PCBM control and $4 \mathrm{vol} \% \mathrm{Fe}_{3} \mathrm{O}_{4}$ NPs samples were taken into consideration for further investigations to find out the mechanism of device performance improvement. $20 \mathrm{vol} \%$ $\mathrm{Fe}_{3} \mathrm{O}_{4}$ NPs samples were also studied in more detail to find out why high volume of NPs harms device performance.

Cross-section TEM images of $230 \mathrm{~nm}$ and $900 \mathrm{~nm}$ samples with 4 and $20 \mathrm{vol} \%$ $\mathrm{Fe}_{3} \mathrm{O}_{4}$ NPs are shown in Figure 3. The gold layer is black marking the interface between air and the active layer. In the process of device fabrication, the cathode is deposited on top of the active layer, so the gold layer marks the position of the cathode. $\mathrm{Fe}_{3} \mathrm{O}_{4}$ NPs are shown as black dots in the images. Since P3HT and PCBM both have significant amount of carbon, so the contrast between the active layer and the embedding materials is not high, but still observable, separated by a blue dashed line. Small amount of $\mathrm{Fe}_{3} \mathrm{O}_{4}$ NPs are trapped in the active layer with random distribution, but the majority of these NPs are aggregated at air interface forming a layer composed of $\mathrm{Fe}_{3} \mathrm{O}_{4} \mathrm{NPs}, \mathrm{P} 3 \mathrm{HT}$ and PCBM. It should be noted that the TEM specimen has a thickness $\sim 80 \mathrm{~nm}$ which is much greater than the $\mathrm{Fe}_{3} \mathrm{O}_{4}$ NP's size (11 nm diameter), and the entire thickness is in focus since the depth of field in the TEM is larger than the specimen thickness. The TEM image is a projection of $80 \mathrm{~nm}$ slice of the active layer in 2-D dimension. So the degree of aggregation of these $\mathrm{Fe}_{3} \mathrm{O}_{4}$ NPs is not known at this point and requires further study. In the future, conductive atomic force microscopy can be applied to characterize the surface current to analyze the distribution of these $\mathrm{Fe}_{3} \mathrm{O}_{4}$ NPs on the top surface. However, it is still challenging to obtain the accurate distribution of these NPs. In Figure 4 phase separation at micrometer length scale caused by $\mathrm{Fe}_{3} \mathrm{O}_{4} \mathrm{NP}$ clusters (black dots) is observed for $20 \mathrm{vol} \%$ NPs samples while it is not seen in other conditions. There are two possible reasons for the $\mathrm{Fe}_{3} \mathrm{O}_{4}$ NPs clustering: 1 . the magnetic 

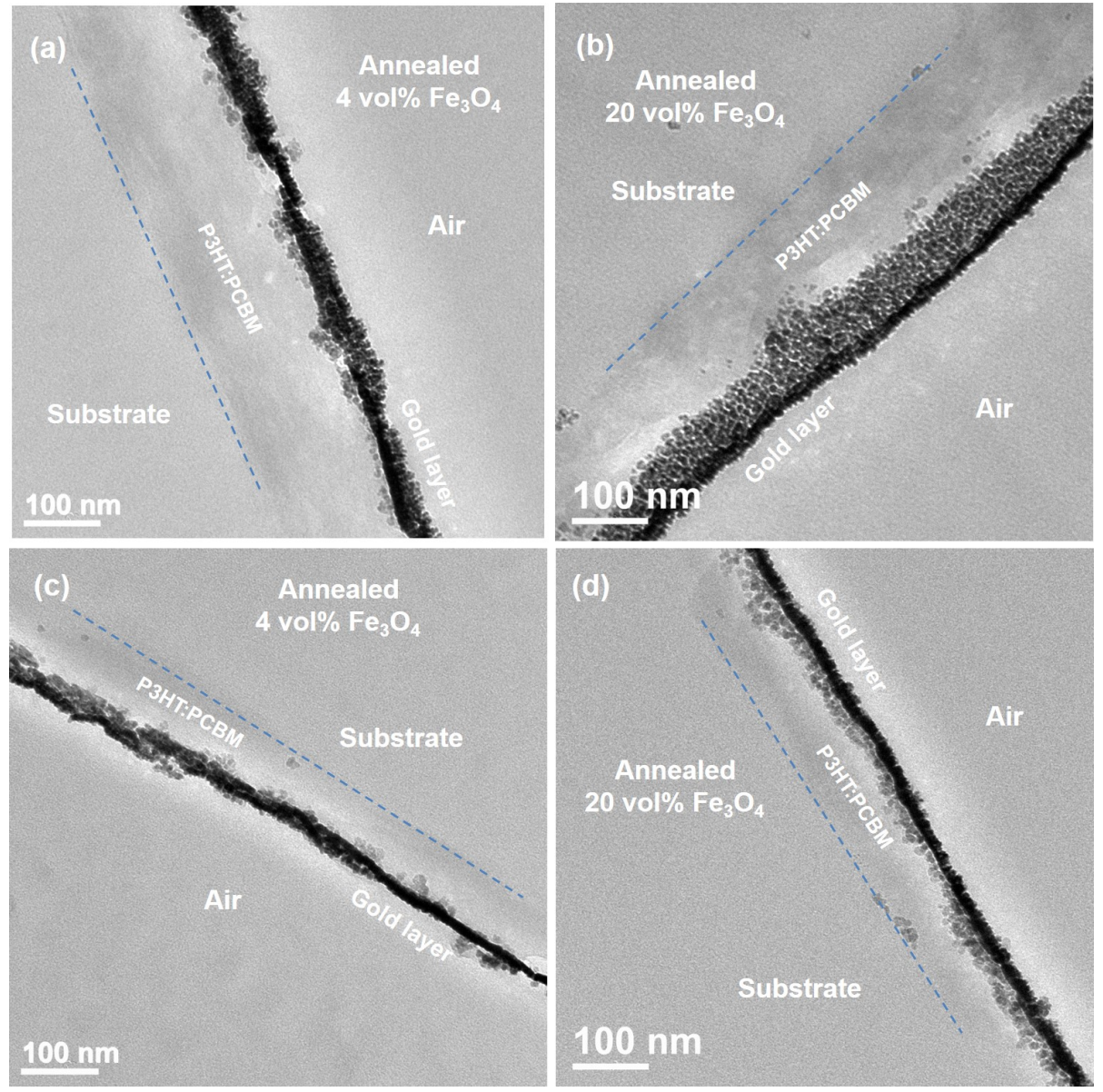

Figure 3: Cross-section TEM images: (a), (b) $230 \mathrm{~nm}$ samples and (c), (d) $90 \mathrm{~nm}$ samples. The majority of $\mathrm{Fe}_{3} \mathrm{O}_{4}$ NPs migrates to the air interface of the active layers for all the samples. 


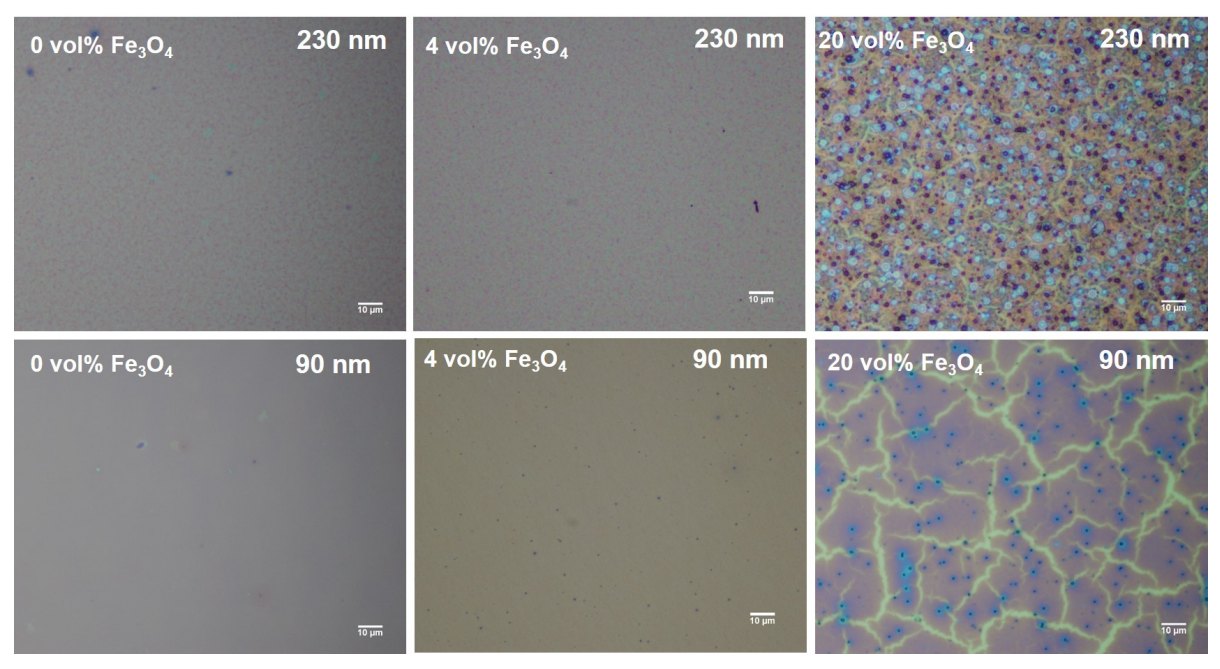

Figure 4: Top view of optical microscopy images from 230 and $90 \mathrm{~nm}$ samples. 20 vol\% $\mathrm{Fe}_{3} \mathrm{O}_{4}$ NPs samples show phase separation at micrometer length scale, while 4 vol\% samples only show some black dots may caused by aggregation of small amount of $\mathrm{Fe}_{3} \mathrm{O}_{4} \mathrm{NPs}$ and this is not seen in 0 vol\% samples. $230 \mathrm{~nm}$ sample with 20 vol\% NPs shows high density of circle objects caused by NP clusters, while their distribution density is much lower in $90 \mathrm{~nm}$ sample.

attraction between $\mathrm{Fe}_{3} \mathrm{O}_{4}$ NPs; 2. the depletion attraction between NPs due to entropic force (causing unbalanced osmotic pressure) in depletion flocculation phenomenon [23]. It is unclear which force plays a more important role causing this clustering.

Figure 5 illustrates the assembly of this multilayer structure. During the spin coating process, P3HT, PCBM and $\mathrm{Fe}_{3} \mathrm{O}_{4}$ NPs move upward to thin the liquid film by convective outflow and solvent evaporation [24]. Afterward, the surface energy of each component, directly related to its refractive index value, determines the materials alignment as described below. Here $n_{i}$ is the refractive index value of component $i$. If we consider a trilayer of air $\left(n_{1}\right)-\mathrm{Fe}_{3} \mathrm{O}_{4} \mathrm{NPs}$ $\left(n_{2}\right)-\mathrm{P} 3 \mathrm{HT}$ :PCBM blend $\left(n_{3}\right)$, then one can tell the structure of air- $\mathrm{Fe}_{3} \mathrm{O}_{4}$ NPs-P3HT:PCBM is stable when $n_{1}<n_{2}<n_{3}$, otherwise it is not stable [17. The refractive index of air has a value of 1 . The refractive indexes of P3HT (1.9) and PCBM (2.0) are close so we assume 1:1 weight ratio P3HT:PCBM has a value of 1.95 [13. The value of $n_{2}$ (1.66) is computed by volume averaging the 


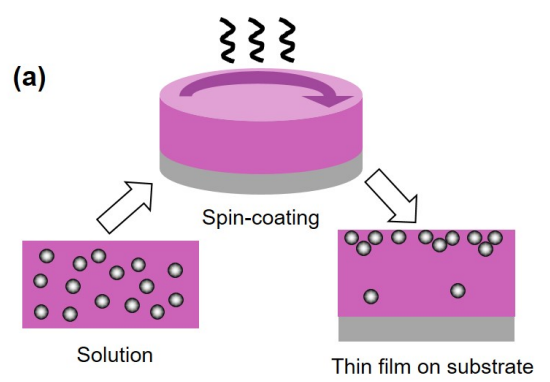

(b)

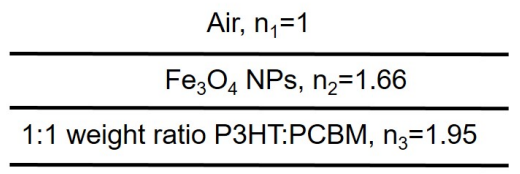

Figure 5: (a) Schematic representation of processing P3HT:PCBM blend with the addition of $\mathrm{Fe}_{3} \mathrm{O}_{4} \mathrm{NPs}$;(b) Illustration of trilayer alignment correlating to each component's refractive index value. But in practice, $\mathrm{P} 3 \mathrm{HT}$ and $\mathrm{PCBM}$ should be able to diffuse between $\mathrm{Fe}_{3} \mathrm{O}_{4} \mathrm{NPs}$ prohibiting the formation of a pure $\mathrm{Fe}_{3} \mathrm{O}_{4}$ layer.

$\mathrm{Fe}_{3} \mathrm{O}_{4}$ inner core with a $3.5 \mathrm{~nm}$ radius (determined by SANS, refractive index 2.42) having a surfactant layer of functionalized oleic acid which is $2 \mathrm{~nm}$ thick (refractive index 1.4). In our recent experiments, these $\mathrm{Fe}_{3} \mathrm{O}_{4}$ NPs were also added to rod coated P3HT:PCBM active layers finding a random distribution of NPs in the vertical direction. Moreover, with the addition of these $\mathrm{Fe}_{3} \mathrm{O}_{4} \mathrm{NPs}$, the device performance was even lower than the control sample. It is because that compared to spin coating, the convective outflow, which plays an important role in moving materials upward, is much weaker in rod coating method. It also points out that simply blending $\mathrm{Fe}_{3} \mathrm{O}_{4}$ NPs into the active layer without the specific structure does not meet the condition improving PCE. This work will be published soon.

Once the air interface is covered by $\mathrm{Fe}_{3} \mathrm{O}_{4}$ NPs with specific surface coverage, the averaged inter-particle distance $\left(d_{s}\right)$ determines the existence of polymer depletion zone which leads to the formation of PCBM rich region for better electron collection at cathode. Therefore, in order to calculate $d_{s}$, surface coverage $(\theta)$ of $\mathrm{Fe}_{3} \mathrm{O}_{4}$ NPs needs to be obtained based on a simple mass balance, given by

$$
\theta=\frac{h}{2 a} \phi_{N P}
$$

where $h$ is the film thickness, $a$ the $\mathrm{Fe}_{3} \mathrm{O}_{4}$ NPs radius and $\phi_{N P}$ the $\mathrm{Fe}_{3} \mathrm{O}_{4}$ 

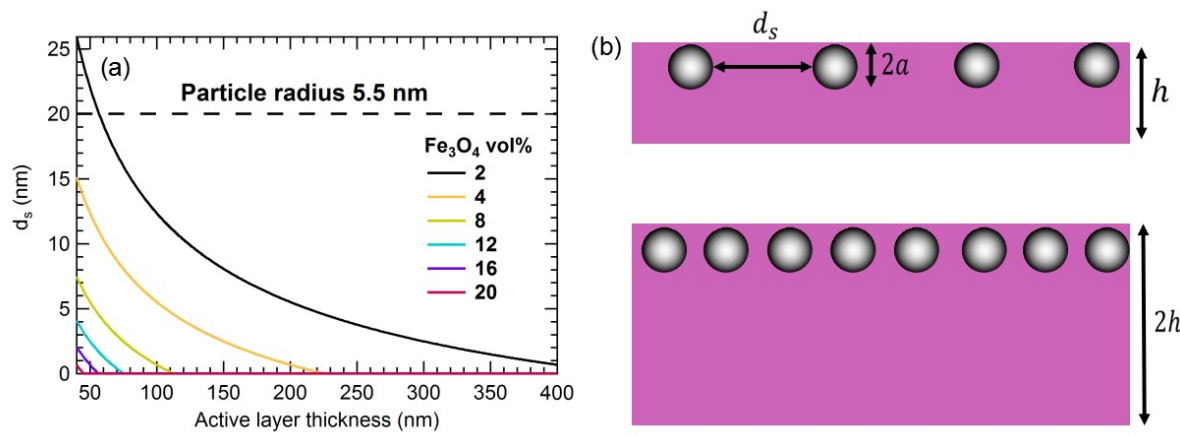

Figure 6: Averaged inter-particle distance as functions of the active layer thickness and $\mathrm{Fe}_{3} \mathrm{O}_{4}$ NPs volume fraction. (a) $d_{s}$ smaller than $20 \mathrm{~nm}$ meets the condition of NP effect;(b) Schematic illustration for the same $\phi_{N P}$, thicker film causes smaller inter-particle distance.

NPs volume fraction in the film. Three assumptions are made here in order to apply this estimate: first, $\phi_{N P}$ in the initial P3HT:PCBM blend of solid content remains the same as in the active layers; second, all $\mathrm{Fe}_{3} \mathrm{O}_{4} \mathrm{NPs}$ migrate to air interface creating a uniform sparse monolayer without considering the $\mathrm{Fe}_{3} \mathrm{O}_{4}$ NP clustering effect; third, film roughness effect was omitted. Hence, deviation from this estimate will be expected since the first two assumptions only loosely hold, and the third even not (see Supporting Information Figure S11). The spacing $d_{s}$ could be obtained from surface coverage for a $2 \mathrm{D}$ monolayer with random distribution packing [25, 26]:

$$
d_{s}=2 a\left(\sqrt{\frac{0.82}{\theta}}-1\right)
$$

When we introduce Equation 1 into Equation 2, the correlation between $d_{s}$ and active layer thickness $(h), \mathrm{NP}$ radius $(a), \mathrm{NP}$ volume fraction $\left(\phi_{N P}\right)$ is determined:

$$
d_{s}=2 a\left(\sqrt{\frac{0.82}{h \cdot \phi_{N P}} \cdot 2 a}-1\right)
$$

This relationship is shown in Figure 6(a) by plotting $d_{s}$ as a function of active layer thickness with a series of $\phi_{N P}$. For the same $\phi_{N P}$, higher thickness results in smaller $d_{s}$, and this is further illustrated in Figure 6(b). Since $R_{g}$ of polydispersed P3HT is about 3-10 nm [19, 20], in order to have polymer (which 


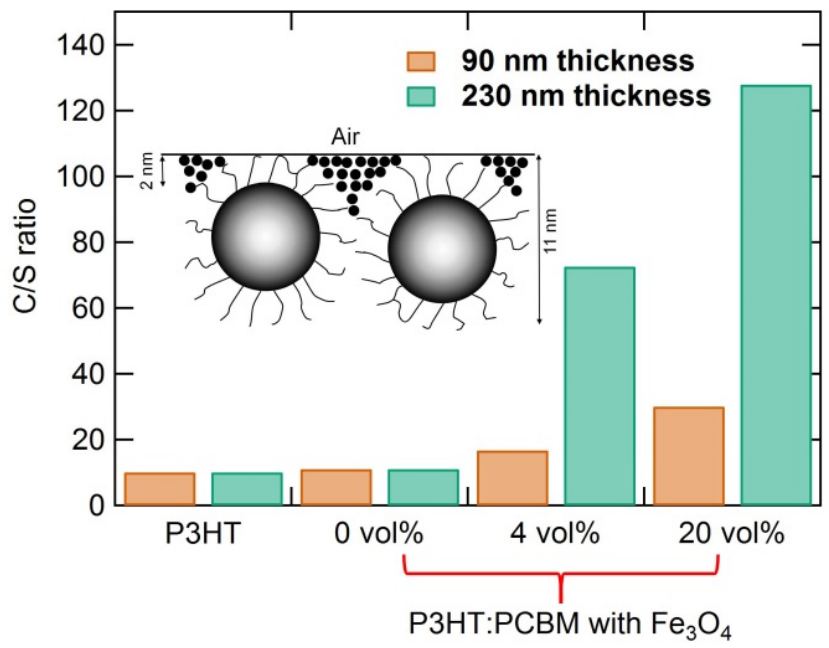

Figure 7: $\mathrm{C} / \mathrm{S}$ atomic ratios at the top surface of samples obtained from XPS. The inset cartoon shows the PCBM molecules filling the gap between $\mathrm{Fe}_{3} \mathrm{O}_{4}$ NPs and air interface.

is $\mathrm{P} 3 \mathrm{HT}$ in this case) depletion zone, $d_{s}$ has to be smaller than $20 \mathrm{~nm}$ (upper limit of P3HT's $2 R_{g}$ ).

For $230 \mathrm{~nm}$ samples, $2 \mathrm{vol} \% \mathrm{Fe}_{3} \mathrm{O}_{4}$ NPs sample has $d_{s}$ as $4.4 \mathrm{~nm}$, while others have close packing NP layer with $d_{s}=0$. For $90 \mathrm{~nm}$ samples, 2, 4 and 8 vol\% $\mathrm{Fe}_{3} \mathrm{O}_{4}$ NPs give $d_{s}$ smaller than $20 \mathrm{~nm}$. However, it should be noted that when $d_{s}$ is smaller than $6 \mathrm{~nm}$ (lower limit of P3HT's $2 R_{g}$ ), keep increasing $\mathrm{Fe}_{3} \mathrm{O}_{4}$ NPs vol\% to have even smaller $d_{s}$ does not provide better morphology for electron collection, because it decreases the amount of PCBM filled in the P3HT depletion zone and possibly results in large amount of $\mathrm{Fe}_{3} \mathrm{O}_{4} \mathrm{NP}$ clusters leading to high series resistance and low fill factor. Therefore, the addition of $\mathrm{Fe}_{3} \mathrm{O}_{4}$ NPs can not improve the device performance of $230 \mathrm{~nm}$ sample, and for $90 \mathrm{~nm}$ samples, $2\left(d_{s}=13.6 \mathrm{~nm}\right)$ and $4\left(d_{s}=6.4 \mathrm{~nm}\right)$ vol\% $\mathrm{Fe}_{3} \mathrm{O}_{4} \mathrm{NPs}$ can enhance PCE, while 8 vol\% NPs $\left(d_{s}=1.3 \mathrm{~nm}\right)$ can not. This estimate can provide guidance for choosing proper film thickness, NP size and NP vol\% to have the polymer depletion flocculation effect (or NP effect for simplicity) working. But, one should always perform experiments to study the practical case considering the deviation from this simple estimate. 
X-ray photoelectron spectroscopy (XPS) is a surface sensitive technique for quantitatively determining the atomic percentages of elements and further obtaining the composition at the sample surfaces. Here we used this method to study whether PCBM rich region existed at cathode interface with the addition of $\mathrm{Fe}_{3} \mathrm{O}_{4}$ NPs. Due to the short inelastic mean free path length of electrons, the probing depth of XPS is about $2 \mathrm{~nm}$ [27, which is close to the thickness of $\mathrm{Fe}_{3} \mathrm{O}_{4}$ NP's surfactant layer, so the signal from iron in the XPS spectra is minimal. The results from Figure 7 compare the $\mathrm{C} / \mathrm{S}$ atomic ratios at the top surfaces of the active layers. A representative of measured XPS spectra of carbon and sulfur is shown in Figure S5. The peak at $284.6 \mathrm{eV}$ is assigned to carbon atoms, and thiophene S atoms give signal at $164.1 \mathrm{eV}$. Carbon (C) 1s signal is from P3HT, PCBM and surfactant layer of $\mathrm{Fe}_{3} \mathrm{O}_{4}$ NPs, sulfur (S) 2p is solely from P3HT. So in this case, one cannot use $\mathrm{C} / \mathrm{S}$ atomic ratio to calculate the weight ratio of $\mathrm{PCBM} / \mathrm{P} 3 \mathrm{HT}$ at the top surfaces as other research groups did before [28, 29, 30. However, since the carbon signal contribution from the surfactant layer is relatively small (see Supporting information section 4), it is reasonable to argue that the increase of $\mathrm{C} / \mathrm{S}$ ratio is significantly affected by the presence of PCBM. The control samples P3HT:PCBM without $\mathrm{Fe}_{3} \mathrm{O}_{4}$ NPs show a $\mathrm{C} / \mathrm{S}$ value close to pure $\mathrm{P} 3 \mathrm{HT}\left(\mathrm{C}_{10} \mathrm{H}_{14} \mathrm{~S}, \mathrm{C} / \mathrm{S}=10\right)$ not depending on active layer thickness, which is in agreement with previous XPS results and neutron reflectivity data [29, 31].

For $90 \mathrm{~nm}$ samples, by adding $\mathrm{Fe}_{3} \mathrm{O}_{4} \mathrm{NPs}, \mathrm{C} / \mathrm{S}$ value increases meaning more PCBM found at the air interface than the control sample. This increase of PCBM is believed to build electron pathway and improve charge collection at cathode interface. And $230 \mathrm{~nm}$ sample has much higher C/S value. As discussed before, this is because $d_{s}$ (the averaged inter-particle distance) is close to zero to exclude the P3HT, while PCBM molecules could fill in the gap between big $\mathrm{Fe}_{3} \mathrm{O}_{4}$ NPs and air interface as illustrated in the inset graph in Figure 7.

Small angle neutron scattering (SANS) is an advanced technique providing the volume average morphological information of samples. The scattering curves for 230 and $90 \mathrm{~nm}$ samples are presented in Figure 8 For $230 \mathrm{~nm}$ samples, the 

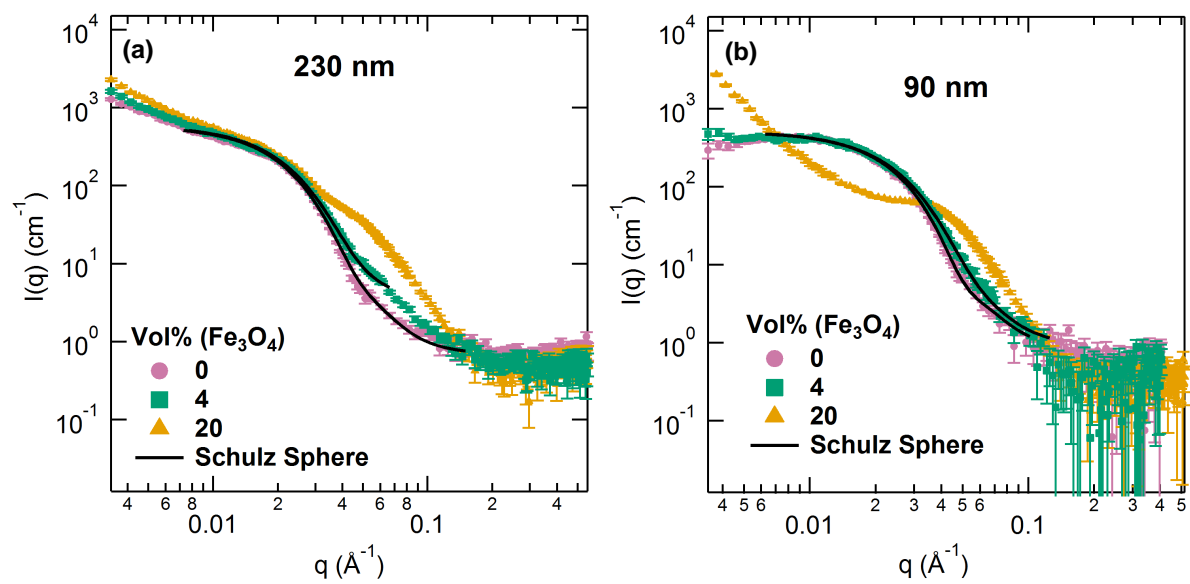

Figure 8: SANS absolute intensity $(I)$ versus wave vector $(q)$ for 230 and $90 \mathrm{~nm}$ samples. The solid lines are fitting curves from polydisperse sphere model with Schulz distribution.

scattering patterns at low- $q$ regime are similar. With a larger amount of $\mathrm{Fe}_{3} \mathrm{O}_{4}$ NPs addition, higher intensity is observed at mid- $q$ regime compared with the control sample, which is also seen in $90 \mathrm{~nm}$ samples. $20 \mathrm{vol} \% \mathrm{Fe}_{3} \mathrm{O}_{4} \mathrm{NPs}$ in $90 \mathrm{~nm}$ sample causes an upturn at low- $q$ regime which suggests a structural difference from other samples. The polydisperse sphere model following a Schulz distribution was used to fit these data. PCBM agglomerates are treated as sphere and the mixed blend of PCBM and P3HT as solvent matrix [14. Hence, $15 \mathrm{~nm}$ sized PCBM agglomerate was obtained from fitting. The size and volume fraction of these PCBM agglomerates are almost not affected by the addition of $\mathrm{Fe}_{3} \mathrm{O}_{4}$ NPs. More fitting results in detail are shown in Table S1.

In order to differentiate the PCBM agglomerates size and volume fraction in an easier observable way, Kratky plots are presented as $q^{2} I(q)$ vs. $q$ in Figure 9 The peak at low- $q$ regime is characteristic from dispersed particles, which are from PCBM agglomerates and $\mathrm{Fe}_{3} \mathrm{O}_{4}$ NPs in this case [32, 33]. The peak position is only affected by particle size, and the height of the peak is influenced by both volume fraction of particles and scattering length density (SLD) contrast between particles and solvent matrix (see Figure S8). Considering the solvent matrix composed of PCBM and P3HT, following the mass balance, the 

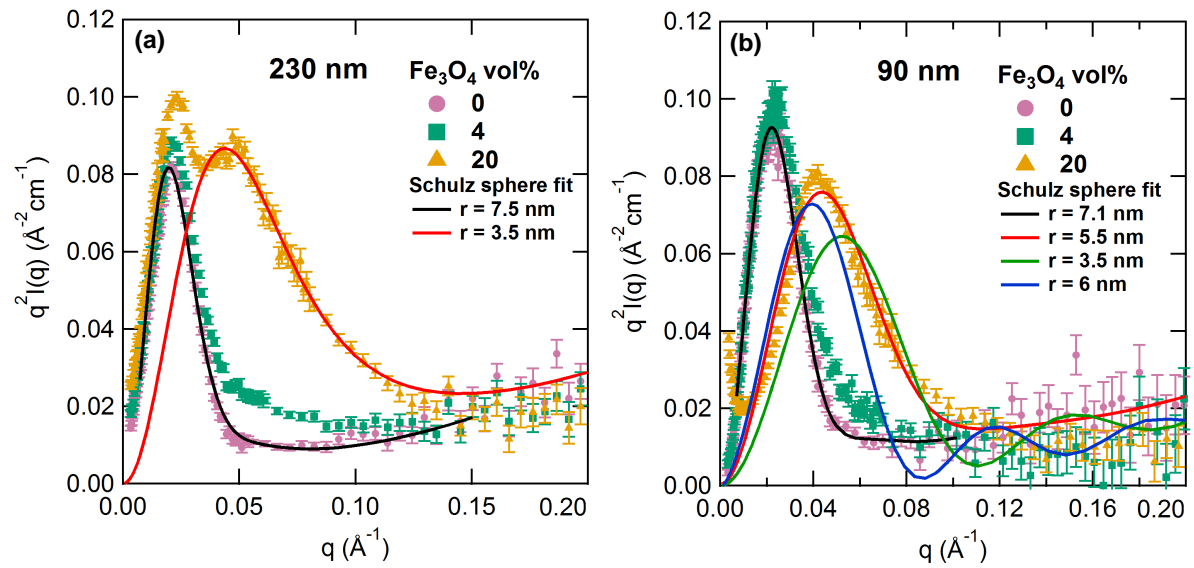

Figure 9: Kratky plots of SANS intensity $(I)$ multiplied by the square of wavevector $(q)$ as a function of $q$ for (a) 230 and (b) $90 \mathrm{~nm}$ samples. The solid fitting curves are from model of Schulz sphere labeled with its radius parameter $(r)$.

change in PCBM agglomerate volume fraction also affects the contrast. Therefore, a higher peak just means more particles and larger contrast at the same time. For $230 \mathrm{~nm}$ samples, agreed with Schulz sphere model fitting, the peaks at $0.02 \AA^{-1}$ have radius of $7.5 \mathrm{~nm}$ and show no significant change with the addition of $\mathrm{Fe}_{3} \mathrm{O}_{4}$ NPs. Because little contrast between the srufactant layer and P3HT:PCBM, 20 vol\% $\mathrm{Fe}_{3} \mathrm{O}_{4}$ NPs cause a peak at $0.047 \AA^{-1}$ representing particles with $3.5 \mathrm{~nm}$ radius, which is the core size of this NP. For $90 \mathrm{~nm}$ samples, PCBM agglomerates have more or less the same size as the thicker samples. However, the 20 vol $\% \mathrm{Fe}_{3} \mathrm{O}_{4}$ NPs sample does not show the twin-peaks as the $230 \mathrm{~nm}$ sample does. Instead, a single peak at $0.042 \AA^{-1}$ featuring particle radius of $5.5 \mathrm{~nm}$ is observed. By using binomial Schulz sphere model, two particle sizes of 6 and $3.5 \mathrm{~nm}$ are obtained which converge into a single one. Hence, PCBM agglomerate has a smaller size with the presence of 20 vol\% $\mathrm{Fe}_{3} \mathrm{O}_{4} \mathrm{NPs}$ in $90 \mathrm{~nm}$ sample. Considering the much faster drying process (spin coating at $1800 \mathrm{rpm}$ ), it may suggest the agglomeration of PCBM is hindered at certain degree when mixed with $\mathrm{Fe}_{3} \mathrm{O}_{4} \mathrm{NPs}$, while $230 \mathrm{~nm}$ sample has much longer solvent evaporation time allowing the agglomeration of PCBM to reach equi- 

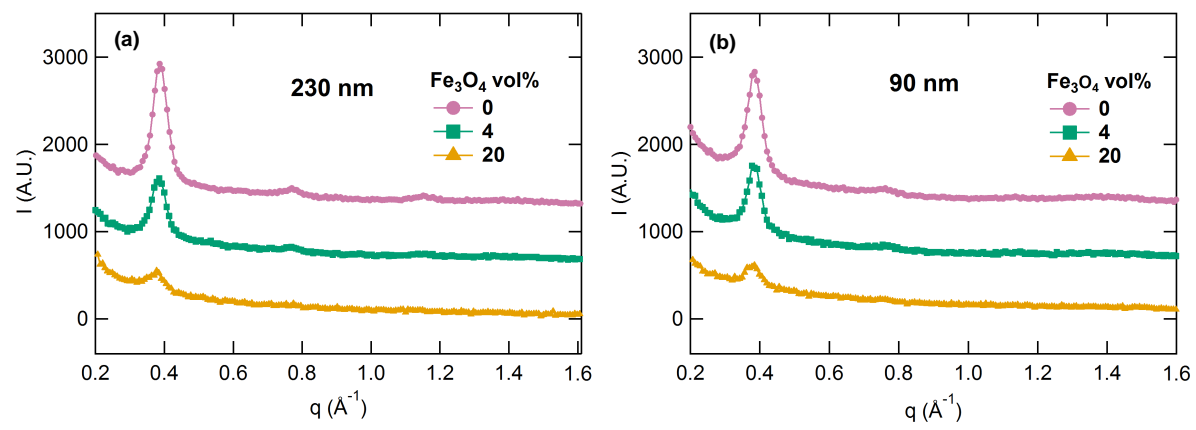

Figure 10: GIXRD intensity $(I)$ as a function of wavevector $(q)$.

librium status and have a larger size. However, the exact mechanism for this phenomenon is still not well understood. Because the scattering curve must reach the origin of the axes $\left(q^{2} I(q)^{2}=0\right.$ when $\left.q=0\right)$, the upturn at low- $q$ regime in $90 \mathrm{~nm}$ sample with $20 \mathrm{vol} \% \mathrm{Fe}_{3} \mathrm{O}_{4}$ NPs must develop into a peak at ultra low- $q$ regime beyond the measured $q$ range suggesting structure formed at micrometer length scale. It is very likely caused by the phase separation in 20 vol\% $\mathrm{Fe}_{3} \mathrm{O}_{4}$ NPs samples' optical microscopy images shown in Figure 4.

Grazing incidence X-ray diffraction (GIXRD) was applied to examine the crystallinity and ordering of P3HT [14, 34]. All diffraction patterns show the (100) reflection centered at $0.38 \AA^{-1}$ corresponding to a $d$ spacing of $16.5 \AA$. With the addition of $4 \mathrm{vol} \% \mathrm{Fe}_{3} \mathrm{O}_{4} \mathrm{NPs}$, the (100) peak intensity slightly decreases meaning lower P3HT crystallinity compared with the control sample. This is because the nucleation process of P3HT disrupted by $\mathrm{Fe}_{3} \mathrm{O}_{4}$ NPs whose size is comparable with the $R_{g}$ of the polymer. And it seems that the addition of 20 vol\% $\mathrm{Fe}_{3} \mathrm{O}_{4}$ NPs results in even lower P3HT crystallinity. However, it should be noted that, for these samples, a layer of close packing $\mathrm{Fe}_{3} \mathrm{O}_{4} \mathrm{NPs}$ is formed at air interface having a thickness of 30-80 nm as shown in TEM images in Figure 3 . The X-ray attenuation length of $\mathrm{Fe}_{3} \mathrm{O}_{4}$ is less than $3 \mu \mathrm{m}$, while the X-ray travel length in this $\mathrm{Fe}_{3} \mathrm{O}_{4}$ thin layer is at least $30 \mathrm{~nm} / \sin 0.5^{\circ}=3.4 \mu \mathrm{m}\left(0.5^{\circ}\right.$ is the X-ray's incident angle) [35]. So the intensity of X-ray drops to less than 1/e ( $e$ is the base of the natural logarithm, $e \approx 2.71828$ ) after passing through this 

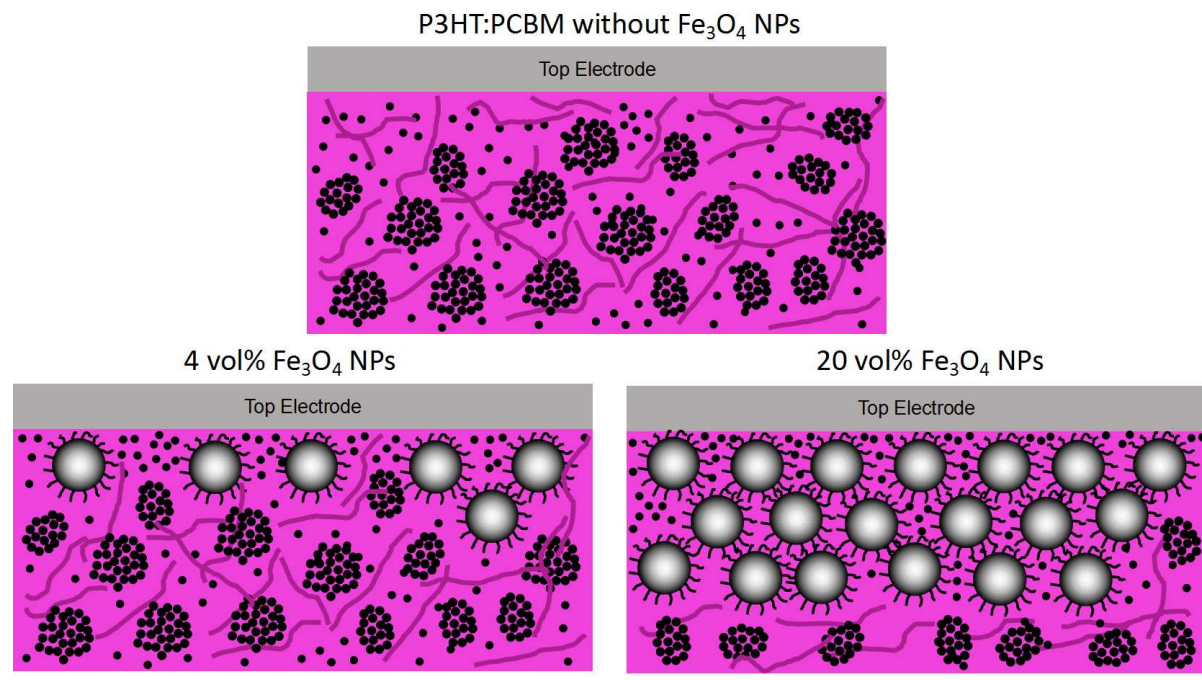

Figure 11: Schematic representation of the NP effect on the morphology near cathode for $90 \mathrm{~nm}$ samples.

$\mathrm{Fe}_{3} \mathrm{O}_{4}$ NPs layer resulting in an inconclusive GIXRD pattern. Nonetheless, it is still reasonable to argue that the addition of $\mathrm{Fe}_{3} \mathrm{O}_{4}$ NPs does not increase the P3HT crystallinity and very possibly decreases it.

Based on the above results and analysis, a set of schematic graphs is showed in Figure 11 to illustrate this synergic NP effect on the morphology of P3HT:PCBM near cathode for $90 \mathrm{~nm}$ samples. 4 vol\% $\mathrm{Fe}_{3} \mathrm{O}_{4}$ NPs helps build electron transport pathways and improve the charge collection by having more PCBM at the cathode. But $20 \mathrm{vol} \% \mathrm{Fe}_{3} \mathrm{O}_{4} \mathrm{NPs}$ form a close packing layer blocking the charge transport and resulting in phase separation at micrometer length scale and high series resistance. This NP effect does not increase the PCBM agglomerate size and even decrease the P3HT crystallinity which are key factors in improving device performance, which proves that this NP effect is the sole reason for this device performance improvement [14]. However, for $230 \mathrm{~nm}$ samples, even 4 vol\% $\mathrm{Fe}_{3} \mathrm{O}_{4}$ NPs added, the distance between them is too small to have enough PCBM near cathode to improve electron conduction as explained before and shown in Figure 6. Therefore, to apply this NP effect to have better 
efficiency, a delicate balance between $\mathrm{Fe}_{3} \mathrm{O}_{4}$ NPs concentration and active layer thickness has to be considered.

\section{Conclusion}

$\mathrm{Fe}_{3} \mathrm{O}_{4}$ NPs were successfully transported to cathode interface forming sparse monolayer by using spin coating method. When the distance between $\mathrm{Fe}_{3} \mathrm{O}_{4}$ NPs is smaller than P3HT's size, polymer depletion zone is formed to exclude P3HT allowing more PCBM near cathode for better electron collection. To fully take advantage of this NP effect to improve device performance, active layer thickness and NPs concentration have to be carefully chosen. The addition of $4 \mathrm{vol} \% \mathrm{Fe}_{3} \mathrm{O}_{4}$ NPs in $90 \mathrm{~nm}$ thick active layer resulted in improvement of P3HT:PCBM solar cell's PCE up to 20\%. For $230 \mathrm{~nm}$ samples, this NP effect is almost negligible since the distance between $\mathrm{Fe}_{3} \mathrm{O}_{4}$ NPs is too small for PCBM to build continuous electron pathways near cathode for better electron collection. Although thicker samples have overall higher efficiency than thinner ones, if we consider the cost of active layer's materials, $90 \mathrm{~nm}$ thick product is cheaper than a $230 \mathrm{~nm}$ one. So if this NP effect could improve thinner device's PCE comparable with a thicker one, the cost of this polymer solar cell can be lowered remarkably by more than half. This NP effect is also believed applicable to other polymer:fullerene systems because of its simple processing method making its future study more intriguing. Furthermore, by combining the concept of light management using colloidal particles [25], there is a bright future for this NP self-assembly method in organic photovoltaics.

\section{Acknowledgements}

This work was supported by NIST Award 70NANB10H256 through the Center for Neutron Science at the University of Delaware. The authors acknowledge the support of the National Institute of Standards and Technology, U.S. Department of Commerce, in providing the neutron research facilities used in this work. 
The authors also thank Prof. David Martin for usage of the UV-vis spectrometer and Prof. Xinqiao Jia for the photoluminescence spectrometer. Mr. Frank Kriss' help on ultramicrotomy and Prof. Chaoying Ni's help on carbon coater are greatly appreciated.

\section{References}

[1] J. Yu, Y. Zheng, J. Huang, Towards high performance organic photovoltaic cells: A review of recent development in organic photovoltaics, Polymers 6 (9) (2014) 2473-2509. doi:10.3390/polym6092473.

[2] H. Youn, H. J. Park, L. J. Guo, Organic photovoltaic cells: From performance improvement to manufacturing processes, Small 11 (19) (2015) 2228-2246. doi:10.1002/smll.201402883.

[3] X. Zhou, W. Belcher, P. Dastoor, Solar paint: From synthesis to printing, Polymers 6 (11) (2014) 2832-2844. doi:10.3390/polym6112832.

[4] M. T. Dang, L. Hirsch, G. Wantz, J. D. Wuest, Controlling the morphology and performance of bulk heterojunctions in solar cells. lessons learned from the benchmark poly(3-hexylthiophene):[6,6]-phenyl- $\mathrm{C}_{61}$-butyric acid methyl ester system, Chem. Rev. 113 (5) (2013) 3734-3765. doi:10.1021/ cr300005u.

[5] K. M. Coakley, M. D. McGehee, Conjugated polymer photovoltaic cells, Chem. Mater. 16 (23) (2004) 4533-4542. doi:10.1021/cm049654n.

[6] Y. Huang, E. J. Kramer, A. J. Heeger, G. C. Bazan, Bulk heterojunction solar cells: Morphology and performance relationships, Chem. Rev. 114 (14) (2014) 7006-7043. doi:10.1021/cr400353v.

[7] A. J. Heeger, 25th anniversary article: Bulk heterojunction solar cells: Understanding the mechanism of operation, Adv. Mater. 26 (1) (2014) 1028. doi:10.1002/adma.201304373. 
[8] D. S. Germack, C. K. Chan, R. J. Kline, D. A. Fischer, D. J. Gundlach, M. F. Toney, L. J. Richter, D. M. DeLongchamp, Interfacial segregation in polymer/fullerene blend films for photovoltaic devices, Macromolecules 43 (8) (2010) 3828-3836. doi:10.1021/ma100027b.

[9] Y. Yang, K. Mielczarek, M. Aryal, A. Zakhidov, W. Hu, Nanoimprinted polymer solar cell, ACS Nano 6 (4) (2012) 2877-2892. doi:10.1021/ nn3001388.

[10] C. Tao, M. Aljada, P. E. Shaw, K. H. Lee, H. Cavaye, M. N. Balfour, R. J. Borthwick, M. James, P. L. Burn, I. R. Gentle, P. Meredith, Controlling hierarchy in solution-processed polymer solar cells based on crosslinked P3HT, Adv. Energy Mater. 3 (1) (2013) 105-112. doi:10.1002/aenm. 201200394 .

[11] S. Moungthai, N. Mahadevapuram, P. Ruchhoeft, G. E. Stein, Direct patterning of conductive polymer domains for photovoltaic devices, Adv. Energy Mater. 4 (8) (2012) 4015-4023. doi:10.1021/am3008328.

[12] J. W. Kiel, M. E. Mackay, B. J. Kirby, B. B. Maranville, C. F. Majkrzak, Phase-sensitive neutron reflectometry measurements applied in the study of photovoltaic films, J. Chem. Phys. 133 (7) (2010) 074902. doi:10.1063/ 1.3471583 .

[13] J. W. Kiel, B. J. Kirby, C. F. Majkrzak, B. B. Maranville, M. E. Mackay, Nanoparticle concentration profile in polymer-based solar cells, Soft Matter 6 (3) (2010) 641-646. doi:10.1039/B920979D.

[14] J. W. Kiel, A. P. R. Eberle, M. E. Mackay, Nanoparticle agglomeration in polymer-based solar cells, Phys. Rev. Lett. 105 (16) (2010) 168701. doi: 10.1103/PhysRevLett.105.168701

[15] M. Stamm, J.-U. Sommer, Polymer-nanoparticle films: Entropy and enthalpy at play, Nat. Mater. 6 (4) (2007) 260-261. doi:10.1038/nmat1880 
[16] M. Cui, T. Emrick, T. P. Russell, Stabilizing liquid drops in nonequilibrium shapes by the interfacial jamming of nanoparticles, Science 342 (6157) (2013) 460-463. doi:10.1126/science.1242852.

[17] R. S. Krishnan, M. E. Mackay, P. M. Duxbury, C. J. Hawker, S. Asokan, M. S. Wong, R. Goyette, P. Thiyagarajan, Improved polymer thin-film wetting behavior through nanoparticle segregation to interfaces, J. Phys.: Condens. Matter 19 (35) (2007) 356003. doi:10.1088/0953-8984/19/35/ 356003 .

[18] P. Jenkins, M. Snowden, Depletion flocculation in colloidal dispersions, Adv. Colloid Interface Sci. 68 (1996) 57-96. doi :10.1016/S0001-8686(96) 90046-9

[19] G. W. Heffner, D. S. Pearson, Molecular characterization of poly(3hexylthiophene), Macromolecules 24 (23) (1991) 6295-6299. doi:10.1021/ ma00023a035

[20] Y. B. Melnichenko, G. D. Wignall, R. N. Compton, G. Bakale, Characterization of fullerenes and fullerene derivatives by small-angle neutron scattering and transmission measurements, J. Chem. Phys. 111 (10) (1999) 4724-4728. doi:10.1063/1.479234

[21] S. Kline, Reduction and analysis of SANS and USANS data using IGOR Pro, J. Appl. Crystallogr. 39 (6) (2006) 895-900. doi:10.1107/ S0021889806035059.

[22] T. P. Russell, H. Ito, G. D. Wignall, Neutron and x-ray scattering studies on semicrystalline polymer blends, Macromolecules 21 (6) (1988) 1703-1709. doi:10.1021/ma00184a029.

[23] S. Asakura, F. Oosawa, Interaction between particles suspended in solutions of macromolecules, J. Polym. Sci. 33 (126) (1958) 183-192. doi: 10.1002/pol.1958.1203312618. 
[24] Y. Chang, W. C. Wu, W. C. Chen, Theoretical analysis on spin coating of polyimide precursor solutions, J. Electrochem. Soc. 148 (4) (2001) F77F81. doi:10.1149/1.1357183.

[25] M. Karg, T. A. F. Konig, M. Retsch, C. Stelling, P. M. Reichstein, T. Honold, M. Thelakkat, A. Fery, Colloidal self-assembly concepts for light management in photovoltaics, Mater. Today 18 (4) (2015) 185-205. doi:10.1016/j.mattod.2014.10.036.

[26] R. S. Krishnan, Nanoparticle induced wetting of polymer films and selfassembled multilayers of nanocomponents, Ph.D. thesis, Michigan State University (2006).

[27] C. J. Powell, A. Jablonski, NIST Electron Inelastic-Mean-Free-Path Database - Version 1.2, National Institute of Standards and Technology, 2010.

[28] I. H. Liu, C. Yi-Ping, F. Jian-Jhih, T. Wei-Hsuan, L. Yu-Bing, C. YuJen, W. Kaung-Hsiung, C. Mei-Hsin, Origins of vertical phase separation in P3HT:PCBM mixed films, Jpn. J. Appl. Phys. 53 (4) (2014) 041601. doi:10.7567/JJAP.53.041601.

[29] Z. Xu, L.-M. Chen, G. Yang, C.-H. Huang, J. Hou, Y. Wu, G. Li, C.-S. Hsu, Y. Yang, Vertical phase separation in poly(3-hexylthiophene): Fullerene derivative blends and its advantage for inverted structure solar cells, Adv. Funct. Mater. 19 (8) (2009) 1227-1234. doi:10.1002/adfm.200801286

[30] B. Reeja-Jayan, A. Manthiram, Influence of polymer-metal interface on the photovoltaic properties and long-term stability of nc-TiO2-P3HT hybrid solar cells, Sol. Energ. Mat. Sol. Cells 94 (5) (2010) 907-914. doi:10. $1016 /$ j.solmat.2010.01.021.

[31] B. W. Guralnick, B. J. Kirby, C. F. Majkrzak, M. E. Mackay, Morphological characterization of plastic solar cells using polarized neutron reflectivity, Appl. Phys. Lett. 102 (8) (2013) 083305. doi:10.1063/1.4793423. 
[32] M. E. Mackay, T. T. Dao, A. Tuteja, D. L. Ho, B. Van Horn, H.-C. Kim, C. J. Hawker, Nanoscale effects leading to non-einstein-like decrease in viscosity, Nat. Mater. 2 (11) (2003) 762-766. doi:10.1038/nmat999.

[33] A. Tuteja, M. E. Mackay, C. J. Hawker, B. Van Horn, Effect of ideal, organic nanoparticles on the flow properties of linear polymers: Noneinstein-like behavior, Macromolecules 38 (19) (2005) 8000-8011. doi: $10.1021 / \mathrm{ma} 050974 \mathrm{~h}$

[34] D. Chen, A. Nakahara, D. Wei, D. Nordlund, T. P. Russell, P3HT/PCBM bulk heterojunction organic photovoltaics: Correlating efficiency and morphology, Nano Lett. 11 (2) (2011) 561-567. doi:10.1021/nl103482n.

[35] C. Chantler, K. Olsen, R. Dragoset, J. Chang, A. Kishore, S. Kotochigova, D. Zucker, X-ray form factor, attenuation, and scattering tables, http://www.nist.gov/pml/data/ffast/ (2001). 
(a)

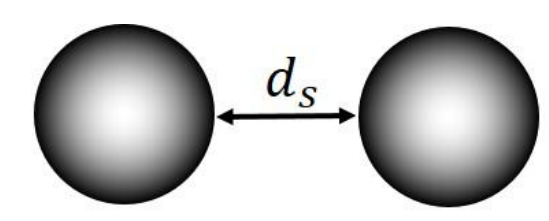

(b)
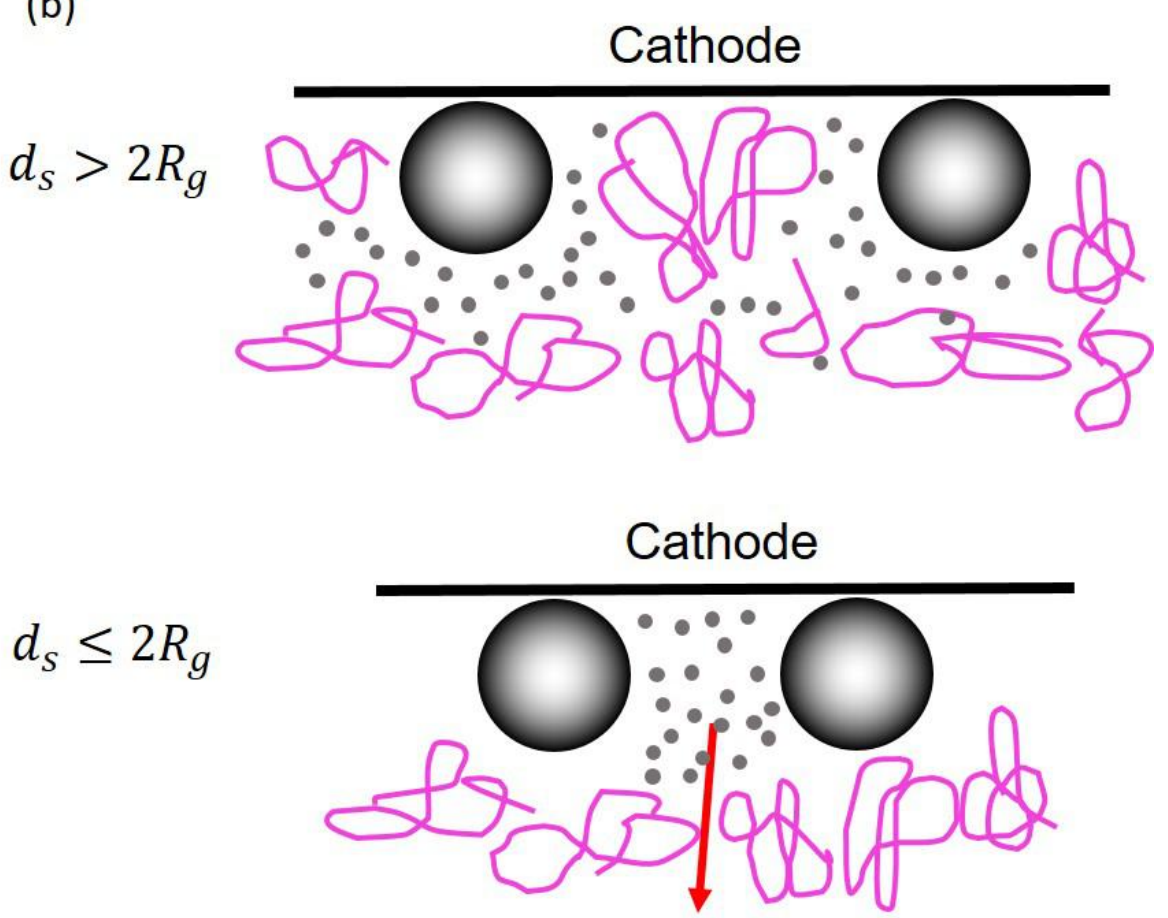

Polymer depletion zone
P3HT:PCBM without $\mathrm{Fe}_{3} \mathrm{O}_{4} \mathrm{NPs}$

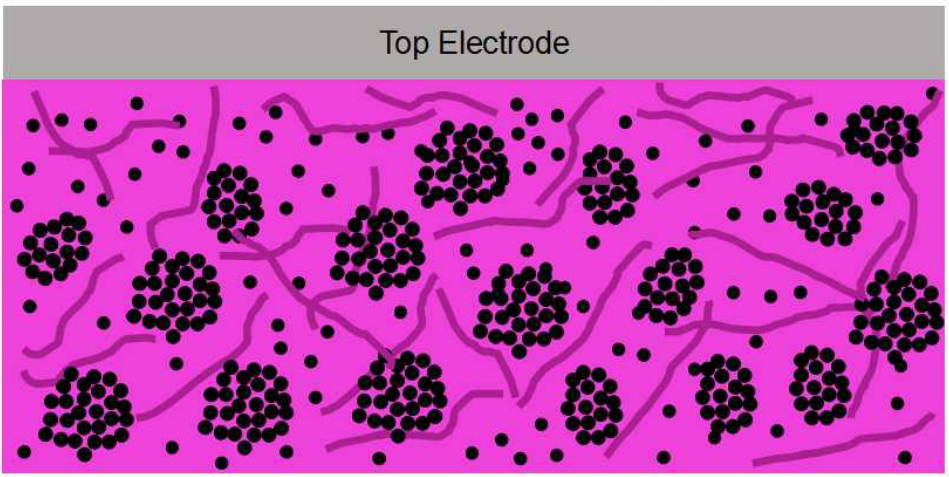

4 vol $\% \mathrm{Fe}_{3} \mathrm{O}_{4} \mathrm{NPs}$

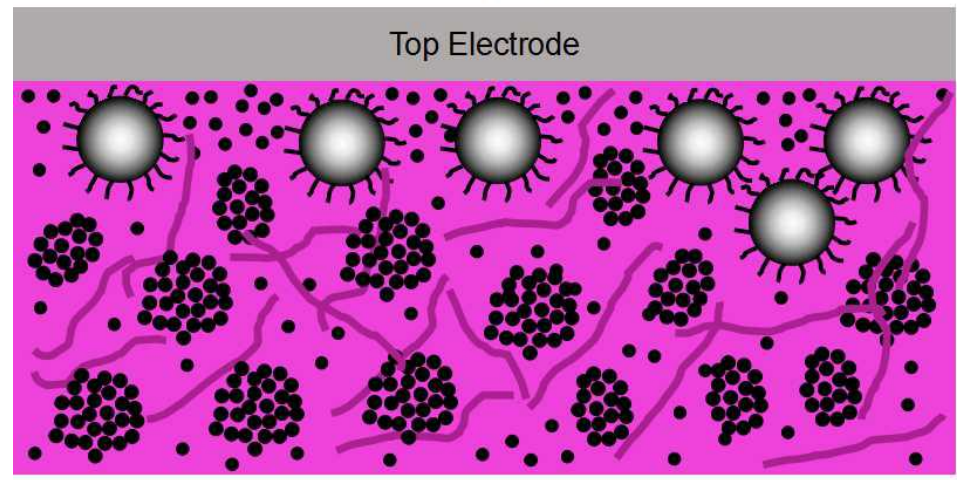

20 vol\% $\mathrm{Fe}_{3} \mathrm{O}_{4} \mathrm{NPs}$

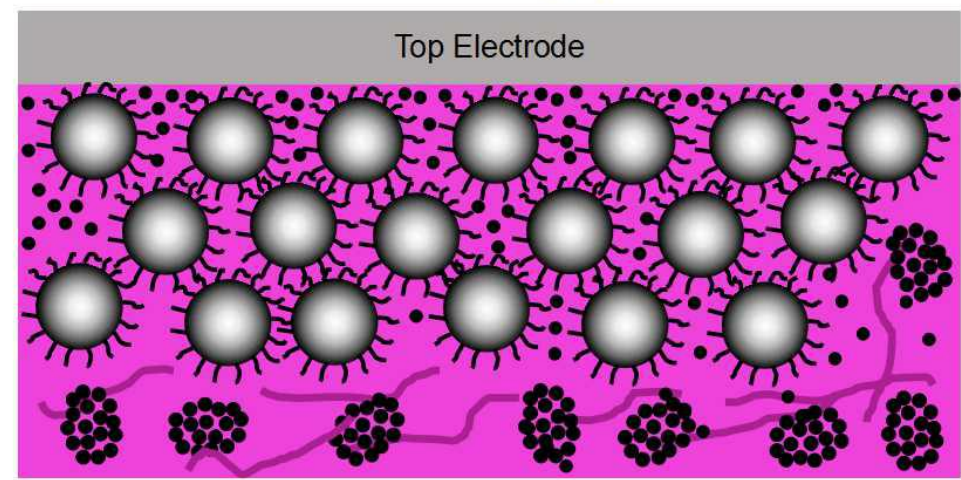

- РСBM \& РЗнт 